\title{
Phytochemical and Network Pharmacology Based Evaluation of Antiepileptic Potential of Identified Metabolites in Argimone mexicana
}

\author{
Vinod Gahlot ${ }^{1}$, Dinesh Kumar Yadav ${ }^{2, *}$
}

\section{Vinod Gahlot ${ }^{1}$, Dinesh Kumar Yadav ${ }^{2, *}$}

'Department of Pharmacology, SGT College of Pharmacy, SGT University, Gurugram, Haryana, INDIA.

2Department of Pharmacognosy, SGT College of Pharmacy, SGT University, Gurugram, Haryana, INDIA.

\section{Correspondence}

Dr. Dinesh Kumar Yadav

Associate Professor, Department of Pharmacognosy, SGT College of Pharmacy, SGT University, Gurugram-122505, Haryana, INDIA.

Phone no: +91 7042348251

Email id: dineshnbri08@gmail.com

History

- Submission Date: 20-07-2021

- Review completed: 30-08-2021;

- Accepted Date: 15-09-2021

\section{DOI : 10.5530/pres.13.4.13}

Article Available online

http://www.phcogres.com

Copyright

(c) 2021 Phcog.Net. This is an openaccess article distributed under the terms of the Creative Commons Attribution 4.0 International license

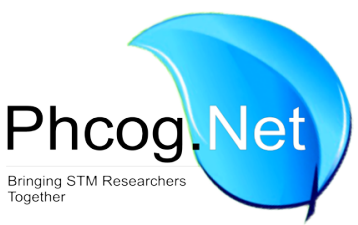

\begin{abstract}
Background: Quality-based assessment of herbal drugs or products is being more concerning for their quality, safety and regulatory purpose. A. mexicana is a traditional herbal medicine that has a long history in the treatment of arthritis, anti-fungal anti-cancer and brain disorders. Aim: Due to lack of scientific evidence based on phytopharmacology, the study is aimed for phytochemical and antiepileptic evaluation of identified metabolites in A. mexicana. Materials and Methods: Phytochemical identification was done using MS, FTIR and ${ }^{1} \mathrm{H}-\mathrm{NMR}$ and quantitated using HPTLC densitometric analysis. Further, ADME and network pharmacology studies were performed to evaluate biological response of identified metabolites. Results: The resulted outcomes of the spectral analysis suggest isolated compounds as ferulic acid, caffeic acid, berberine and angoline. In HPTLC quantitative analysis, the content of ferulic acid, caffeic acid, berberine and angoline was found as $3.475 \pm 0.028,1.036 \pm 0.013,0.714 \pm 0.014$ and $0.738 \pm 0.081 \mu \mathrm{g} / \mathrm{mg}$ of A. mexicana extract. In ADME analysis, berberine and angoline showed good bioavailable response while in network pharmacology analysis, except angoline, all the metabolites significantly interacted with several genes (SOD1, NOS, MAPK3, UGT1As, G6PD, ACOT2, BAAT etc) associated with brain ischemia, oxidative and inflammatory stress or the genes response for elimination of toxins from the body. Conclusion: Hence, the study enlightens that $A$. mexicana possess several major and minor metabolites and which can be the key parameter for further quality and regulatory based assessment of $A$. Mexicana and biological role against oxidative and inflammatory stress induced epileptic seizure.
\end{abstract}

Key words: Argemone mexicana L., Phytoconstituents, HPTLC, ADME analysis, Network pharmacology.

\section{INTRODUCTION}

The application for authentication and reliable quality studies are the principal requirement for herbal raw materials or medicinal plants used under the traditional system of medicine including the Indian system of medicine, the Chinese system of medicine etc. ${ }^{[1,2]}$ Historically, medicinal plants have been used in the treatment of various disorders from a long time while many of the traditional scripture classify them as per their applicability, accessibility and admissibility to cure, treat and nullify the disease or any deleterious effects arise in the body's system. ${ }^{[3]}$ Due to the complex matrix of phytoconstituents in medicinal plants works with multidimensional therapeutic approaches. Quality assessment of the medicinal plants becomes the major challenge for the current official quality control mode. ${ }^{[4]}$ A few bioactive markers were chosen only for qualitative and quantitative assay which characterize the authenticity of the targeted or selected medicinal plant of interest. Referring to many minor and major

bioactive constituents present in herbal preparations, it is impossible to pinpoint every single bioactive constituent in the herbal drug, qualitatively and quantitatively. ${ }^{[5]}$ However, the analytical techniques such as high-performance thin-layer chromatography (HPTLC), high-performance liquid chromatography (HPLC), liquid chromatography-mass spectrometry (LCMS), gas chromatography-mass spectrometry (GCMS), ion-exchange chromatography and gelpermeation (molecular sieve) chromatography, affinity chromatography and paper chromatography are associated with qualitative and quantitative evaluation of medicinal plants and provides the standard and authentic scientific with aspects to their safety and regulatory purpose. ${ }^{[6,7]}$ Moreover, chromatographic techniques such as column chromatography and HPTLC are one of the widely used and cost-effective methods for qualitative and quantitative evaluation of medicinal plants or even

Cite this article: Gahlot V, Yadav DK. Phytochemical and Network Pharmacology based Evaluation of Oxidative and Inflammatory Stress Induced Antiepileptic Potential of Identified Metabolites of Argemone mexicana L. Pharmacog Res. 2021;13(4):208-17. 
provide the best methods over the quality control techniques. Major advantages of HPTLC are its reliability in the quantification of analytes at micro and even in nanogram levels and even useful to detect the huge number of compounds with high resolution and detection approaches. Automation of sample application, detection (spraying or dipping), closed developing chambers providing standardized conditions (relative humidity, saturation, drying), and digital documentation systems for capturing chromatograms are the essential tools in HPTLC. ${ }^{[8,9]}$ Because of easy handling and great progress in instrumentation leading to the reproducibility of data, HPTLC will remain the most important technique for qualitative analysis of plants. With its extreme flexibility concerning choices of mobile phases and detection methods, the technique can cope with the diversity of substances from primary and secondary metabolism. ${ }^{[10]}$

A. mexicana commonly known as Ghamoya or Satyanashi (family: Papaveraceae) is found in almost every part of the world and distribution in many tropical and sub-tropical countries including Asia and Africa. In India, It is commonly found on roadsides and fields as well and it is considered one of the important medicinal plants in India. ${ }^{[1]}$ The yellow juicy part was exuded when the plant is injured, has long been used in India as traditional medicine for dropsy, scabies, ophthalmic, jaundice, and cutaneous affections. In the modern system of medicine, it is widely used for brain disorders, anti-fungal and anti-cancer etc. ${ }^{[12,13]}$ Not only juice but different parts of this plant are used in chronic disorders. The seeds and their oil are frequently employed as a remedy for asthma, ulcers, dysentery, and other intestinal affections. ${ }^{[11]}$ The leaves and seeds have been used in snakebites or anti-venom properties. ${ }^{[14]}$ Flowers are found to be expectorant and have been used in the treatment of coughs. ${ }^{[15]}$ Besides, its infusion finds application against hypertension and inflammatory. ${ }^{[13]}$ However, quality control evaluation of $A$. mexicana still evaded its authenticity. Quality control analyses based on qualitative and quantitative evaluation of phytoconstituents make us far formalized from its safety, efficacy and regulatory purpose and generate such scientific evidences which help us to protect the drug origin from spurious or adulterants belongs to the same species even pharmaceuticals also.

Taking all these into consideration, the present study is aimed for isolation and characterization of phytoconstituents using modern chromatographical and spectroscopical tool and development of simple, accurate and rapid HPTLC method for quantification of phytoconstituents in the hydroalcoholic extract of A. Mexicana at a single platform. The method has been validated as per the ICH guidelines. Further, in-silico analysis was conducted to explore the biological relevance of identified metabolites. Hence, the present prospective of the study is to generate scientific evidences which do not only oblige the quality standardization of plant/ its plant-based herbal formulations but also biological mechanistic relevance in terms to treat or cure epileptic seizure induced by oxidative and inflammatory stress.

\section{MATERIALS AND METHODS}

TLC Silica gel $60 \mathrm{~F}_{254}$ aluminum sheet, double distilled water, HPLC water were purchased from sigma whereas 60-120\# size silica gel and 230- 400\# size silica gel purchased from Sisco Research Laboratories Pvt. Ltd, New Delhi, India. The organic or inorganic solvents were used of analytical grade.

\section{Collection and authentication of plant}

A total of $1 \mathrm{~kg}$ fresh plant material was collected from the local region of Delhi NCR and authenticated by CSIR- National Institute of Science Communication and Information Resources. The plant specimen was submitted to the Raw Material Herbarium and Museum with the

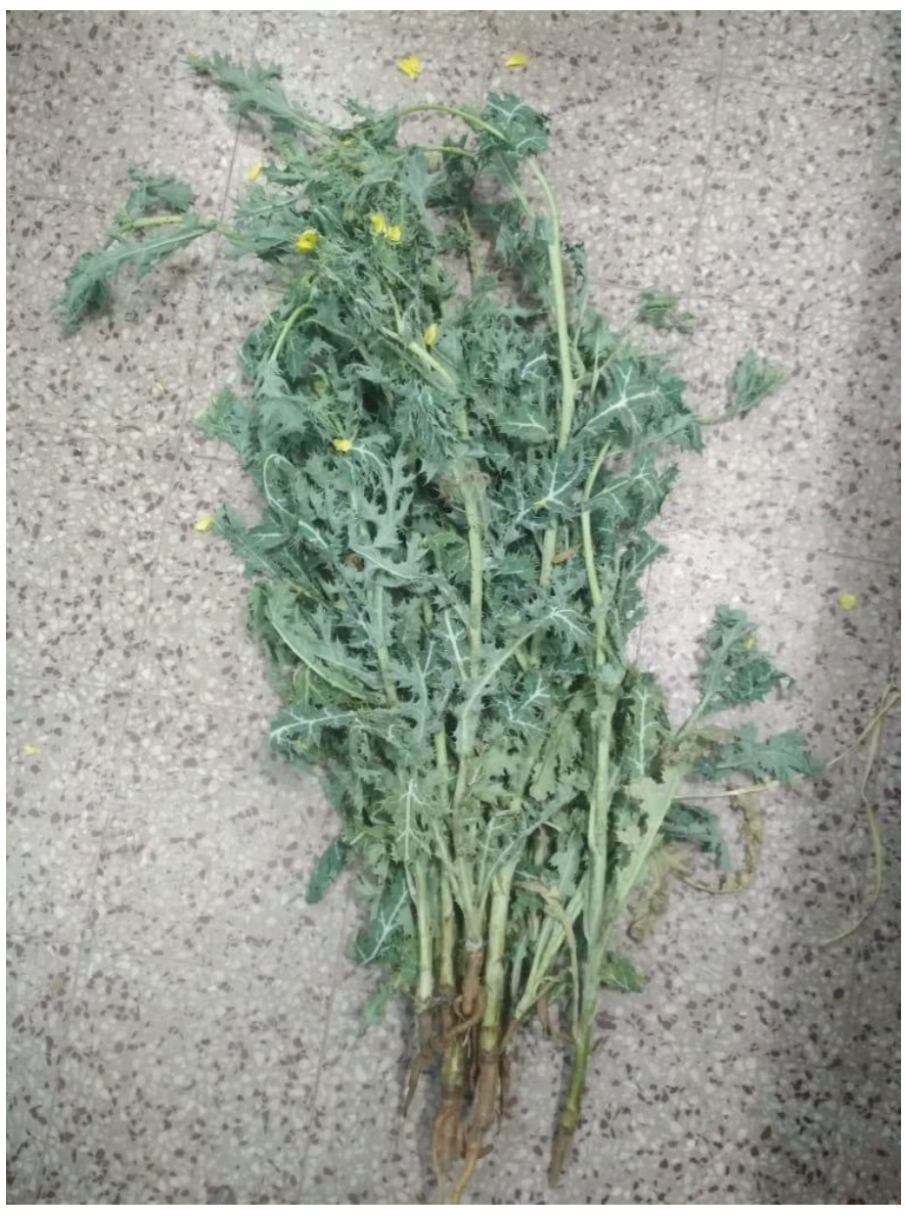

Figure 1: A. mexicana plant.

authentication number NISCAIR/RHMD/Consult/2020/3660-61. The collected plant material has been displayed in Figure 1.

\section{Preparation of extract}

The plant material was shade dried for one week and the whole plant was coarsely powdered. The powdered material $(500 \mathrm{~g})$ was processed for the extraction by the reflux method for $8 \mathrm{hrs}$ at $60^{\circ} \mathrm{C}$ temperature using 2.8 $\mathrm{L}$ of extracting solvent. The hydroalcoholic solvent system was prepared using methanol and distilled water in 7:3 v/v ratio. After the period of extraction, the content was filtered using a muslin cloth and Whatman's filter paper and the filtrate was dried on a water bath at $60^{\circ} \mathrm{C}$ temperature till complete evaporation of the solvent. After all, the solid residue was obtained and stored in an airtight container for further analysis. During the same period, the extractive value of the sample was calculated for record purposes. ${ }^{[16,17]}$ The plant material and extracted yield have been displayed in Figure 1.

\section{Column chromatography}

Column chromatography (CC) was performed for the separation of phytoconstituents from the complex matrix of $A$. mexicana hydroalcoholic extract and their further separation for pure constituent using different gradients of the solvent system. In brief, $5 \mathrm{~g}$ of extract was loaded or adsorbed on $15 \mathrm{~g}$ of silica gel (60-120 mesh size) while the size silica gel (230- 400 mesh size) used for column packing, the sample loaded on silica gel was subjected to the column (column length $\times$ diameter $(40 \times 3 \mathrm{~cm})$ ) for separation of phytoconstituents in a gradient manner using chloroform and methanol as the mobile phase. Each collected fraction was of $10 \mathrm{ml}$ 
volume capacity. The flow rate of eluted solvent during CC was set at $3 \mathrm{ml} / \mathrm{min}$. During CC process, each collected fraction was estimated for the separation of a single constituent by thin-layer chromatography (TLC) using toluene, ethyl acetate and formic acid as mobile phase in different necessary compositions.

\section{Spectral analysis of isolated compounds}

Mass spectrometric (MS) analysis of isolated compounds

The isolated compounds from hydroalcoholic extract of A. mexicana were analyzed through MS analysis. The compound was identified based on their molecular mass obtained from the spectral data. In brief, The MS analysis was performed on Water's ACQUITY UPLC ${ }^{(\mathrm{TM})}$ system (Waters Corp., MA, USA) adjoined with an auto-sampler, binary solvent delivery system, column manager and a tunable MS detector. Four samples of $1 \mathrm{mg} / \mathrm{ml}$ concentration were prepared in LCMS grade solvent, acetonitrile (A: $85 \%$ ) and water (B: 15\%) were used as chromatographic solvent run throughout a monolithic capillary silica-based $\mathrm{C}_{18}$ column (ACQUITY UPLC(R) BEH C $18.7 \mu \mathrm{m}, 2.1 \times 100 \mathrm{~mm}$ ) the injection volume for sample was set at $2 \mu \mathrm{l}$. The flow rate of the nebulizer gas and cone gas was set at $500 \mathrm{~L} / \mathrm{h}$ and $50 \mathrm{~L} / \mathrm{h}$, respectively. In mass analysis electrospray ionisation (ESI) was used as the ion source and the temperature for mass source was fixed at $120^{\circ} \mathrm{C}$ while capillary and cone voltage was set at 3.0 and $40 \mathrm{KV}$, respectively. For collision, argon was active at a pressure of $5.5 \times 10^{-5}$ torr. The obtained spectral data were interpreted and tentatively identified phytoconstituents based on their $\mathrm{m} / \mathrm{z}$ value from mass data sources such as Mass Bank, ChemSpider, etc as well as literature. ${ }^{[3]}$

\section{${ }^{1} \mathrm{H}-\mathrm{NMR}$ spectroscopic analysis of isolated compounds}

NMR spectroscopical analysis of isolated compounds was performed as per the described method using Bruker Avance $400 \mathrm{MHz}$ and $100 \mathrm{MHz}$ NMR spectrometer. Each sample was dissolved in deuterated methanol-d4 (CD3OD) as NMR solvent while tetramethylsilane was used as an internal standard. In brief, the above-isolated sample was dried under high vacuum pressure to remove traces of solvent. The resulting residue was dissolved in dimethyl sulfoxide (DMSO) as a standard solvent then the sample proceeded for spectroscopic analysis by NMR technique. ${ }^{[18,19]}$

\section{FT-IR spectroscopy analysis of isolated compounds}

The spectral analyses of isolated compounds were performed by using Win-IR, Bio-Rad FTS spectrophotometer. In brief, $1 \mathrm{mg}$ of isolated sample was mixed with potassium bromide to form a solid pallet and well ahead proceed for spectroscopical analysis under the range of 4000 to $400 \mathrm{~cm}^{-1}$. [20]

\section{HPTLC analysis of A. mexicana hydroalcoholic extract and quantitative analysis for isolated compounds}

$30 \mathrm{mg}$ of $A$. mexicana hydroalcoholic extract was dissolved in methanol using vortex followed by filtration using a PTFE membrane filter of $0.2 \mu \mathrm{M}$. The stock solution $(1 \mathrm{mg} / \mathrm{ml})$ of ferulic acid, caffeic acid, berberine and angoline were prepared. Thereafter, $6 \mu \mathrm{L}$ of the sample and different concentration $(0.2-2.0 \mu \mathrm{L})$ of each standard was applied with the help of Camag Linomat-V with a $6 \mathrm{~mm}$ wide band length to different pre-washed and activated Silica gel $60 \mathrm{~F}_{254}$ pre-coated HPTLC plates $(10 \mathrm{x} 10 \mathrm{~cm})$. The nitrogen flow delivery speed was set up to $130 \mathrm{~nL} / \mathrm{s}$. Toluene, ethyl acetate, glacial acetic acid, methanol $(6: 3: 1: 1, \mathrm{v} / \mathrm{v} / \mathrm{v})$ were used as a solvent system to develop plate 1 containing 3 markers (ferulic acid, caffeic acid and berberine) while toluene, ethyl acetate, glacial acetic acid, methanol $(5: 4: 1: 1, \mathrm{v} / \mathrm{v} / \mathrm{v})$ were used as solvent system to develop the TLC plates containing sample and angoline as marker in a pre-saturated TLC development chamber. Each plate was developed to a distance of $7.5 \mathrm{~cm}$ at room temperature $\left(25^{\circ} \mathrm{C}\right)$. After drying, the spots on the developed plate were visualized under visible (white), short UV $(254 \mathrm{~nm})$, and long UV $(366 \mathrm{~nm})$ light. The quantification studies of ferulic acid, caffeic acid, berberine and angoline were carried out at $254 \mathrm{~nm}$ as per ICH guide line and the content of each marker in the sample was expressed in $\mu \mathrm{g} / \mathrm{mg}(\mathrm{w} / \mathrm{w}){ }^{[21]}$

\section{ADME analysis}

ADME analysis for ferulic acid, caffeic acid, berberine and angoline was established through the computational tool "SwissADME (http:// www.swissadme.ch/index.php)”. TPSA (Topological Polar Surface Area (TPSA) for drug integrity, Consensus Log Po/w for drug lipophilicity, Log Kp (skin permeation) and drug-likeness were predicted as the standard parameters for consideration of their bioavailable or ADME response. Further, the comparative analysis of each corresponding parameter was done to determine the relationship between molecular integrity and their bioavailable response.

\section{Network construction of active components common target}

In the network construction analysis, the ligation efficacy of each selected gene was predicted. Gene Ontology (GO) analysis through Metascape Gene Analysis (metascape.org) tool was performed to evaluate multiple physiological roles of each gene in the regulation of kidney and associated disorders after the analysis of compound-disease common target. A protein-protein interaction (PPI) network and compound-proteins interaction were obtained based on the STRING platform (https:// string-db.org/) and Cytoscape (version 3.8.2) software. The target PPI was constructed and imported to Cytoscape software for interaction information, integration and further protein ligated construction analysis. The analysis covered all the nearly functional interactions among the expressed proteins-proteins and compound-proteins.

\section{Statistical representation}

The data were expressed in Mean \pm SD for significant evaluation of experimental outcomes. The measurements were taken in triplicate for better consideration of chromatographical outcomes in HPTLC analysis.

\section{RESULTS}

The extraction process for $A$. mexicana hydroalcoholic extract was done successfully. The obtained yield was found as $13.27 \%(\mathrm{w} / \mathrm{w})$ which was used for further studies.

\section{Column chromatography}

The column chromatography method was done successively using chloroform (A) and methanol (B) as mobile phases for the separation of phytoconstituents from the complex matrix of $A$. mexicana hydroalcoholic extract. During chromatographic separation, gradient mode of the mobile phase was applied in different ratio as $100 \% \mathrm{~A}$ and $0 \% \mathrm{~B}$ for collection of 20 fractions, $95 \% \mathrm{~A}$ and $5 \% \mathrm{~B}$ for collection of 30 fractions, $90 \% \mathrm{~A}$ and $10 \% \mathrm{~B}$ for collection of 18 fractions, $85 \% \mathrm{~A}$ and $15 \% \mathrm{~B}$ for collection of 33 fractions, $80 \%$ A and $20 \%$ B for collection of 37 fractions and $75 \% \mathrm{~A}$ and $25 \% \mathrm{~B}$ used or collection of 38 fractions. Each fraction was collected of $10 \mathrm{ml}$ volume capacity. During CC process, the solvent polarity was only increased when no separation was occurred which was confirmed by TLC while the individual fraction pointed with single spot of separated compound was collected and concentrated for further analysis. The chromatographic results reveal that the fraction numbers $28-31,55-57,83-87$ and 104-109 were confirmed as single compound fractions and the remaining was obtained as a mixture of compounds. In a simple and more understanding schematic representation, the 
<smiles>COc1cc(/C=C/C(=O)O)ccc1O</smiles>

Ferulic acid<smiles>COc1ccc2c[n+]3c(cc2c1OC)-c1cc2c(cc1CC3)OCO2</smiles>

Berberine<smiles>O=C(O)/C=C/c1ccc(O)c(O)c1</smiles>

Caffeic acid

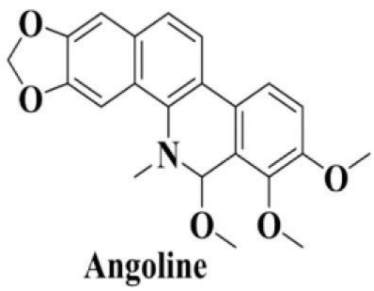

Figure 2: Chemical structure of identified metabolites in A. mexicana extract.

outcomes of chromatographic separation have been summarized in Figure 2.

\section{Spectroscopic analysis}

The MS, FTIR and ${ }^{1}$ HNMR spectral analyses of isolated compounds from A. mexicana hydroalcoholic extract were performed to identify the compounds. NMR spectroscopy of the isolated compounds was performed using TMS as an internal standard. In spectral analysis, the MS spectral data of compound 1 showed an intense signal of $194.71 \mathrm{~m} / \mathrm{z}$. In FTIR analysis, the principal absorption peaks were appeared at $3378.13 \mathrm{~cm}^{-1}$ due to the presence of- $\mathrm{COOH}$ and $-\mathrm{OH}$ groups. The identified peaks at the frequency range 2985.20 and $2912.28 \mathrm{~cm}^{-1}$ due to the presence of $=\mathrm{CH}_{2}$, and $-\mathrm{CH}_{3}$ stretching. The most significant part of the spectrum was bands that appeared at 1659.22 and $1488.97 \mathrm{~cm}^{-1}$ due to the presence of ketone $(-\mathrm{C}=\mathrm{O})$ and $\mathrm{C}-\mathrm{O}-\mathrm{C}$ stretching vibration. The resulted data suggests being the presence of the phenolic compound. The ${ }^{1} \mathrm{HNMR}$ spectral data of compound 1 showed three aromatic protons at $\delta 7.12$, $6.98,6.38(3 \mathrm{H} \mathrm{d}, \mathrm{d}, \mathrm{m})$ respectively. The signals showed at $\delta 11.18$ and $9.78(2 \mathrm{H}, 2 \mathrm{~s})$ represents for carboxyl and phenol group. Two signals for the ethylene group appeared in the aliphatic region at $\delta 7.47$ and 6.28 $(2 \mathrm{H}, 2 \mathrm{~d})$ while an intense peak appeared at $\delta 3.88(3 \mathrm{H}, \mathrm{s})$ for protons of methoxy group which reveals the presence of ferulic acid as reported in the previous findings also. ${ }^{[22]}$

The MS spectral data of compound 2 showed an intense signal of $180.36 \mathrm{~m} / \mathrm{z}$. In FTIR analysis, the main absorption peaks appeared at 3487.29, $3012.28,1663.84$ and $1512.26 \mathrm{~cm}^{-1}$ were appeared due to stretching of $-\mathrm{COOH},-\mathrm{OH},-\mathrm{CH}_{2},-\mathrm{C}=\mathrm{O}$ and $-\mathrm{C}-\mathrm{O}-\mathrm{C}$ stretching vibration. The resulted data suggests being the presence of the phenolic compounds. The ${ }^{1} \mathrm{HNMR}$ spectral data of compound 2 showed three aromatic protons at $\delta 7.14,6.98,6.35(3 \mathrm{H} \mathrm{d}, \mathrm{d}, \mathrm{m})$ respectively. The signals showed at $\delta 11.15$ and $9.79(2 \mathrm{H}, 2 \mathrm{~s})$ represents for carboxyl and phenol group. Two signals for the ethylene group appeared in the aliphatic region at $\delta 7.47$ and $6.28(2 \mathrm{H}, 2 \mathrm{~d})$. The spectral results and previous findings strongly emphasize to the caffeic acid as compound $2 .^{[23]}$

The MS spectral data of compound 3 showed an intense signal of 366.52 $\mathrm{m} / \mathrm{z}$. In FTIR analysis, the main absorption peaks appeared at 3532.14, $3381.75,3045.22$ and $2934.55 \mathrm{~cm}-1$ due to stretching vibration of $-\mathrm{N} / \mathrm{N}^{+}$, $-\mathrm{CH}_{2}$, and $-\mathrm{CH}_{3}$ group. Further, the absorption peaks at 1607.27, 1469.39, $1351.98,600.28 \mathrm{~cm}^{-1}$ are due to stretching vibration of $-\mathrm{C}=\mathrm{C},-\mathrm{C}-\mathrm{O}-\mathrm{C}$ and asymmetric carbons. The resulted data suggests being the presence of an alkaloid compound. In the ${ }^{1} \mathrm{HNMR}$ spectral data of compound 3 , the six protons of the aromatic methoxy group appeared at $\delta 3.81(6 \mathrm{H}, \mathrm{s})$. The four protons of the isoquinoline ring appeared at $\delta 6.75(\mathrm{H}, \mathrm{d}), 7.04$ $(\mathrm{H}, \mathrm{m}), 8.53(\mathrm{H}, \mathrm{d})$ and $10.19(\mathrm{H}, \mathrm{s})$, respectively. The two protons of the dioxolane ring appeared at $\delta 5.92(2 \mathrm{H}, \mathrm{s})$ position. The obtained data were matched with the reported data which strongly supports compound 3 as berberine. ${ }^{[24]}$

The MS spectral data of compound 4 showed an intense signal of 379.39 $\mathrm{m} / \mathrm{z}$. In FTIR analysis, the main absorption peaks appeared at 3522.03, $3107.49,3002.57 \mathrm{~cm}^{-1}$ due to the stretching vibration of tertiary amine $(-\mathrm{N}),-\mathrm{CH}_{2},-\mathrm{CH}_{3}$ group. the absorption peaks at $1487.51,1348.67$ and $1033.27 \mathrm{~cm}^{-1}$ due to stretching vibration of $-\mathrm{C}-\mathrm{O}-\mathrm{C},-\mathrm{C}-\mathrm{H}$ or asymmetric carbons. The spectral data of compound 4 reveals the presence of alkaloid compound having ether group skeletal. The ${ }^{1} \mathrm{HNMR}$ spectral data of compound 4 reveals twelve aromatic methoxy and tertiary amine proton at $\delta 2.98,3.31,3.79,3.89(12 \mathrm{H}, 4 \mathrm{~s})$, respectively. The two protons of the dioxolane ring appeared at $\delta 6.15(2 \mathrm{H}, \mathrm{s})$ position. Four $-\mathrm{CH}$ proton of appeared in the aromatic region at $\delta 6.75,7.12,7.37$ and 7.49 positions. The data was matched with the reported values which reveal the presence of angoline as compound $4 .{ }^{[25,26]}$

The spectra's of MS, FT-IR, ${ }^{1} \mathrm{HNMR}$ and the predicted structures of isolated compounds have been displayed in Figure 3-6 (supplementary files).

\section{HPTLC profiling and quantitative estimation of ferulic acid, caffeic acid, angoline and berberine}

HPTLC profiling and quantitative estimation of ferulic acid, caffeic acid, angoline and berberine in the hydroalcoholic extract of A. mexicana were performed successively. The resulted data reveals several numbers of minor and major metabolites at a different wavelength $(254 \mathrm{~nm}$ and $366 \mathrm{~nm}$ ) in the complex matrix of hydroalcoholic extract of A. mexicana while validation parameters for quantification of ferulic acid, caffeic acid, berberine and angoline was found linear, accurate, and robust in the wide range of 200-2000 ng/spot. The limit of detection (LOD) and the limit of quantitation (LOQ) for ferulic acid, caffeic acid, berberine and angoline were found as 13.501, 17.096, 10.304, $20.119 \mathrm{ng} / \mathrm{spot}$ and $40.913,51.807,31.226,60.967 \mathrm{ng} / \mathrm{spot}$, respectively. The inter-day and intra-day precision were determined as percentage relative standard deviation or the coefficient of variation and the results were expressed in the range found as $0.325-2.107,0.198-2.652,0.210-1.578,0.374-2.154 \%$ and $0.384-1.925,0.196-2.538,0.347-1.682,0.284-1.219 \%$, respectively. The accuracy of the developed method was determined as the percentage drug recovered by percentage spiking $0,50,100$, and $150 \%$ of the standard to the sample in pre-analyzed samples at $2000 \mathrm{ng} / \mathrm{spot}$ which exhibited recovery in the range of 99.186-99.926, 99.290-99.781, 99.815100.077 and 99.106-99.385 \% for ferulic acid, caffeic acid, berberine and angoline. Thereafter, the content of each marker was calculated in the hydroalcoholic extract of $A$. mexicana which was found as $3.475 \pm 0.028$, $1.036 \pm 0.013,0.714 \pm 0.014$ and $0.738 \pm 0.081 \mu \mathrm{g} / \mathrm{mg}$ of the extract at $0.68,0.56,0.16$ (plate $\mathrm{A}^{\prime}$ ), and $0.27 \mathrm{R} f$ (plate B'), respectively. HPTLC plate view at $254 \mathrm{~nm}$ and chromatograms for hydroalcoholic extract of A. mexicana, marker constituents and their respective chromatograms have been displayed in Figure 7.

\section{ADME analysis}

SwissADME is one of the proficient and admirable in-silico online tools for computational analysis of drugs (synthetic or natural compounds) to evaluate pharmacokinetics, drug-likeness and medicinal chemistry friendliness. ${ }^{[27]}$ It gives robust data to predict the bio-response of the targeted molecules. ADME analysis of isolated compounds was performed based on SwsisADME online computational tool by using the unique 
molecular code of the compound as Canonical smiles. The parameters such as TPSA, iLOGP, XLOGP3, WLOGP, MLOGP, Silicos-IT Log P etc were estimated. The predicted observation of each metabolite has been summarized in Table 1. Consensus Log is the average value of all the lipophilic parameters revealed high gastrointestinal (GI) absorption and lipophilicity while blood-brain barrier (BBB) permeability showed also high. The permeability strength was expressed as $\log \mathrm{Kp}(\mathrm{cm} / \mathrm{s})$ and the bioavailability Score of each targeted compounds was found as 0.85 and 0.55 which represents its availability to the therapeutic site. ADME analysis of each metabolite with their solubility radar plots is summarized in Figure 4.

\section{Network Construction of Compound-Disease Common Targets \\ Common target network (protein-protein interaction)}

Fifty seven putative target genes were used in the process of network construction while 52 genes were interconnected each other and potentially associated in pathophysiology for oxidative and inflammatory stress induced epileptic seizures. A protein-protein interaction network was imported from the STRING database for analysis and network establishment. The selected target interaction network was established with a medium confidence score of 0.400 . The established network embodied 52 numbers of nodes, 188 numbers of edges, 7.23 average node degree and 0.631 as average local clustering coefficient. In the constructed network the expected number of edges was found 43 while PPI enrichment $p$-value $<1.0 \mathrm{e}-16$. Besides, the established proteinprotein network has significantly more interactions than expected. The significant interaction of each protein/target gene is based on proteins of similar size selected from the genome database and characterized that the proteins are at least partially biologically connected in each other during oxidative and inflammatory stress induced epileptic seizures. In the Figure, the edges characterize the interaction between sets of potential targets, while the nodes characterize the targets. The intensity of target interaction is represented with the target degree value (Figure 5).

Further, the target genes were analyzed for Gene Ontology (GO) through Metascape Gene Analysis (metascape.org) to evaluate the multiple physiological roles of each gene in the regulation of oxidative and inflammatory stress induced epileptic seizures. Out of 94 analyzed genes, the top twenty results were selected which were directly interrelated with the pathophysiology and analyzed for further assessments. The observation of enriched terms across input gene revealed that many targeted genes play a vital role in response to nutrient level, brain ischemia, signaling by interleukins, regulation of lipoprotein particle level and inflammatory and oxidative response, positive regulation of cell death, dopamine metabolism, etc. ${ }^{[28]}$ The bar graph of enriched terms across input gene lists, colored by p-values and the summary of enrichment analysis have been summarized in Figure 6.

\section{DISCUSSION}

Herbal medicines are the growing need of the human beings to face several ailments due to their easy assessability, affordability, and least side effects. ${ }^{[3]}$ Besides, qualitative and quantitative evaluation is one of the critical needs for the assessment of herbal medicine or products based on their unique pattern of metabolites which helps to generates scientific evidence comprehended to concern their safety, efficacy and regulatory prospectus. ${ }^{[29]}$ The present prospective of study provides a simple, authentic and robust scientific evidences for quality based assessment of A. mexicana using chromatographical and spectroscopical techniques at a single platform which play role in its evation from multiple misleading species as adulterant. ${ }^{[30]}$

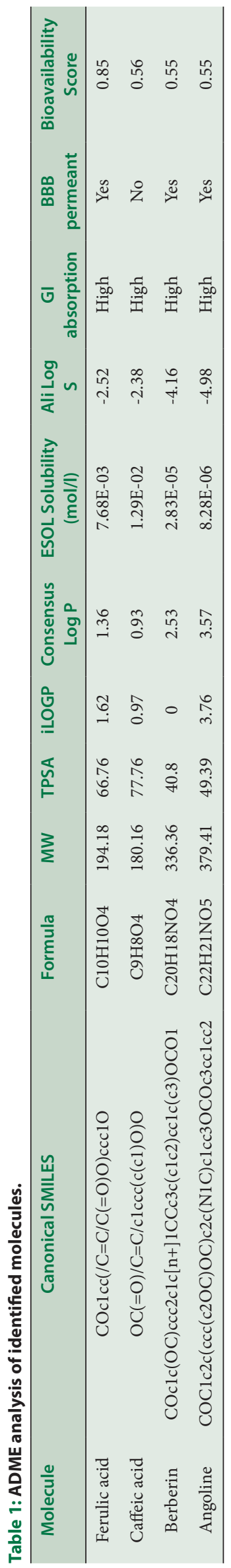


Table 2: List of selected genes with Uniport ID.

\begin{tabular}{|c|c|c|c|}
\hline Sr.no. & Gene name & Protein name & Uniport ID \\
\hline 1. & GLXR2 & 2-hydroxy-3-oxopropionate reductase & G0F006 \\
\hline 2. & CYP1A1 & Cytochrome P450 1A1 & P04798 \\
\hline 3. & G6PD & Glucose-6-phosphate 1-dehydrogenase & P11413 \\
\hline 4. & UCP2 & Mitochondrial uncoupling protein 2 & P55851 \\
\hline 5. & SULT1A4 & Sulfotransferase $1 \mathrm{~A} 4$ & PODMN0 \\
\hline 6. & NFKBIB & NF-kappa-B inhibitor beta & Q15653 \\
\hline 7. & SLC22A16 & Solute carrier family 22 member 16 & Q86VW1 \\
\hline 8. & SULT1A1 & Sulfotransferase $1 \mathrm{~A} 1$ & P50225 \\
\hline 9. & IL17A & Interleukin-17A & Q16552 \\
\hline 10. & CXCL2 & C-X-C motif chemokine 2 & P19875 \\
\hline 11. & NOS3 & Nitric oxide synthase, endothelial & P29474 \\
\hline 12. & CYP1A2 & Cytochrome P450 1A2 & P05177 \\
\hline 13. & PCSK9 & Proprotein convertase subtilisin/kexin type 9 & Q8NBP7 \\
\hline 14. & UTG1A1 & UDP-glucuronosyltransferase 1A1 & Q64550 \\
\hline 15. & TYR & Tyrosyl-DNA phosphodiesterase 2 & O95551 \\
\hline 16. & GATA2 & Endothelial transcription factor GATA 2 & P23769 \\
\hline 17. & STK11 & Serine/threonine-protein kinase STK11 & Q15831 \\
\hline 18. & PLA2G10 & Group 10 secretory phospholipase A2 & O15496 \\
\hline 19. & HP & & \\
\hline 20. & PLA2G2A & Phospholipase A2, membrane associated & P14555 \\
\hline 21. & DECR1 & 2,4-dienoyl-CoA reductase [(3E)-enoyl-CoA-producing], mitochondrial & Q16698 \\
\hline 22. & SLC22A8 & Solute carrier family 22 member 8 & Q8TCC7 \\
\hline 23. & AHR & Aryl hydrocarbon receptor & P35869 \\
\hline 24. & ACOT1 & Acyl-coenzyme A thioesterase 1 & Q86TX2 \\
\hline 25. & SLC2A4 & SLC2A4 regulator & Q9NR83 \\
\hline 26. & SULT1C2 & Sulfotransferase $1 \mathrm{C} 2$ & O00338 \\
\hline 27. & MAPK3 & Mitogen-activated protein kinase 3 & P27361 \\
\hline 28. & CYCS & Cytochrome c & P99999 \\
\hline 29. & BAAT & Bile acid-CoA:amino acid $\mathrm{N}$-acyltransferase & Q14032 \\
\hline 30. & BECN1 & Beclin-1 & Q14457 \\
\hline 31. & KCNQ1 & Potassium voltage-gated channel subfamily KQT member 1 & P51787 \\
\hline 32. & DAXX & Death domain-associated protein 6 & Q9UER7 \\
\hline 33. & ALOX15 & Polyunsaturated fatty acid lipoxygenase ALOX15 & P16050 \\
\hline 34. & HNF4G & Hepatocyte nuclear factor 4-gamma & Q14541 \\
\hline 35. & ADIPOQ & Adiponectin receptor protein 1 & Q96A54 \\
\hline 36. & MMP9 & Matrix metalloproteinase-9 & P14780 \\
\hline 37. & ALDH7A1 & Alpha-aminoadipic semialdehyde dehydrogenase & P49419 \\
\hline 38. & ACOT2 & Acyl-coenzyme A thioesterase 2, mitochondrial & P49753 \\
\hline 39. & LPL & Lipoprotein lipase & P06858 \\
\hline 40. & SOD1 & Superoxide dismutase $[\mathrm{Cu}-\mathrm{Zn}]$ & P00441 \\
\hline 41. & NOS2 & Nitric oxide synthase, inducible & P35228 \\
\hline 42. & SULT1A2 & Sulfotransferase $1 \mathrm{~A} 2$ & P50226 \\
\hline 43. & MAU2 & MAU2 chromatid cohesion factor homolog & Q9Y6X3 \\
\hline 44. & MAPK1 & Mitogen-activated protein kinase 1 & P28482 \\
\hline 45. & UGT1A7 & UDP-glucuronosyltransferase 1A7 & Q9HAW7 \\
\hline 46. & MIF & MIF4G domain-containing protein & A9UHW6 \\
\hline 47. & VMP1 & Vacuole membrane protein 1 & Q96GC9 \\
\hline 48. & NRF1 & Endoplasmic reticulum membrane sensor NFE2L1 & Q14494 \\
\hline 49. & HMOX1 & Heme oxygenase 1 & P09601 \\
\hline 50. & AIFM1 & Apoptosis-inducing factor 1, mitochondrial & O95831 \\
\hline 51. & NME1 & Nucleoside diphosphate kinase A & P15531 \\
\hline 52. & SLC22A7 & Solute carrier family 22 member 7 & Q9Y694 \\
\hline 53. & LDLR & Sortilin-related receptor & Q92673 \\
\hline 54. & COMT & Catechol O-methyltransferase & P21964 \\
\hline 55. & PGD & Prostaglandin-H2 D-isomerase & P41222 \\
\hline
\end{tabular}




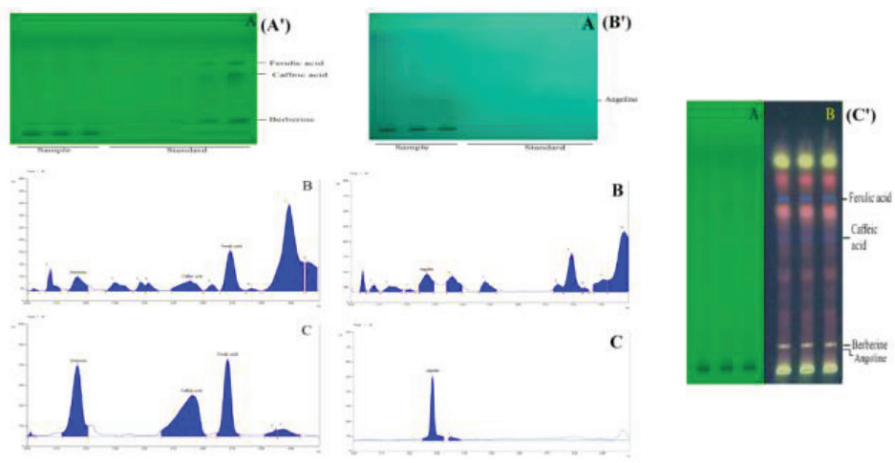

Figure 3: HPTLC profiling and quantification of ferulic acid, caffeic acid, angoline and berberine in the hydroalcoholic extract of $A$. mexicana. Figure $A^{\prime}(A)$ showing the developed HPTLC plate at $254 \mathrm{~nm}$ for ferulic acid, caffeic acid and berberine. Figure $A^{\prime}(B$ and $C$ ) showing the chromatograms of $A$. mexicana extract and standards. Figure $B^{\prime}(A)$ showing the developed HPTLC plate at $254 \mathrm{~nm}$ for sample and angoline. Figure $B^{\prime}(B$ and $C)$ showing the chromatograms of $A$. mexicana extract and angoline. Figure $C^{\prime}(A$ and $B)$ showing fingerprinting of hydroalcoholic extract of $A$. mexicana at 254 and $366 \mathrm{~nm}$.

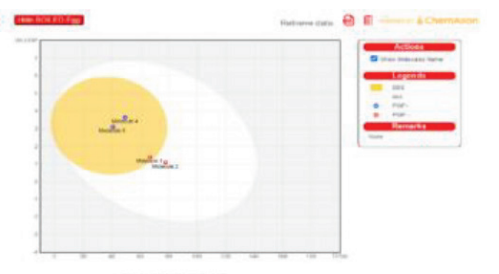

ADME plot

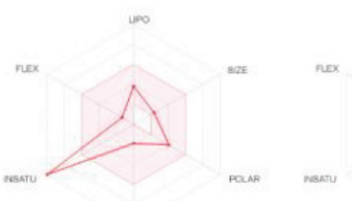

Molecule 2

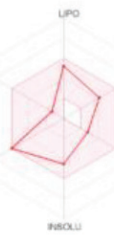

Molecule 3

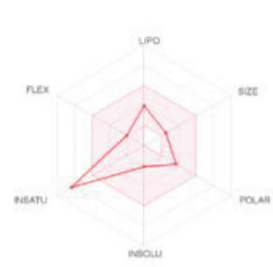

Molecule 1
Figure 4: ADME analysis of identified metabolites, molecule 1 represents radar plot for ferulic acid, molecule 2 represents the radar plot of caffeic acid, molecule 3 represents the radar plot of berberine and molecule 4 represents the radar plot of angoline.

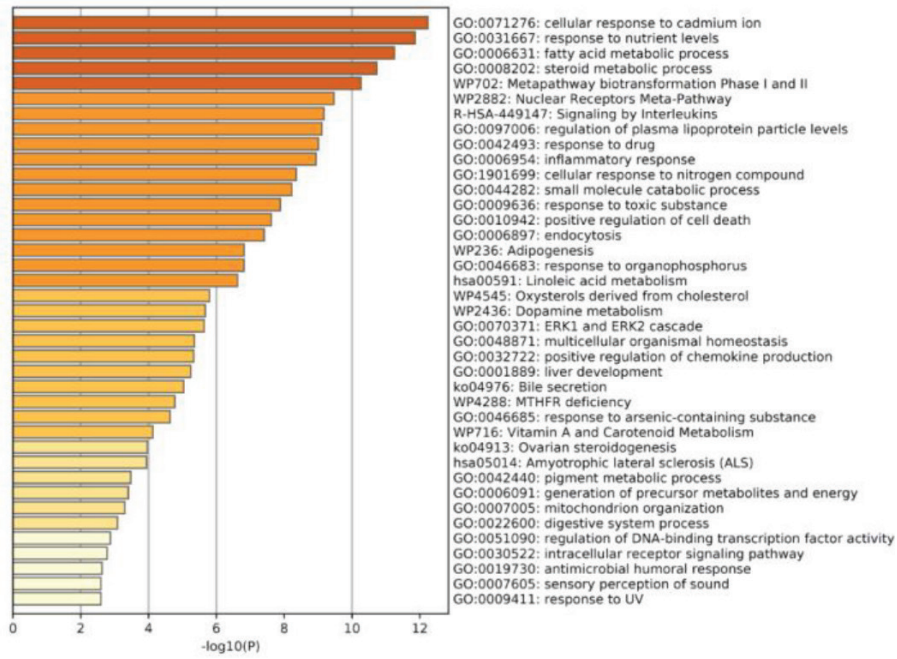

Figure 5: Gene ontology (biological process) of the selected genes.

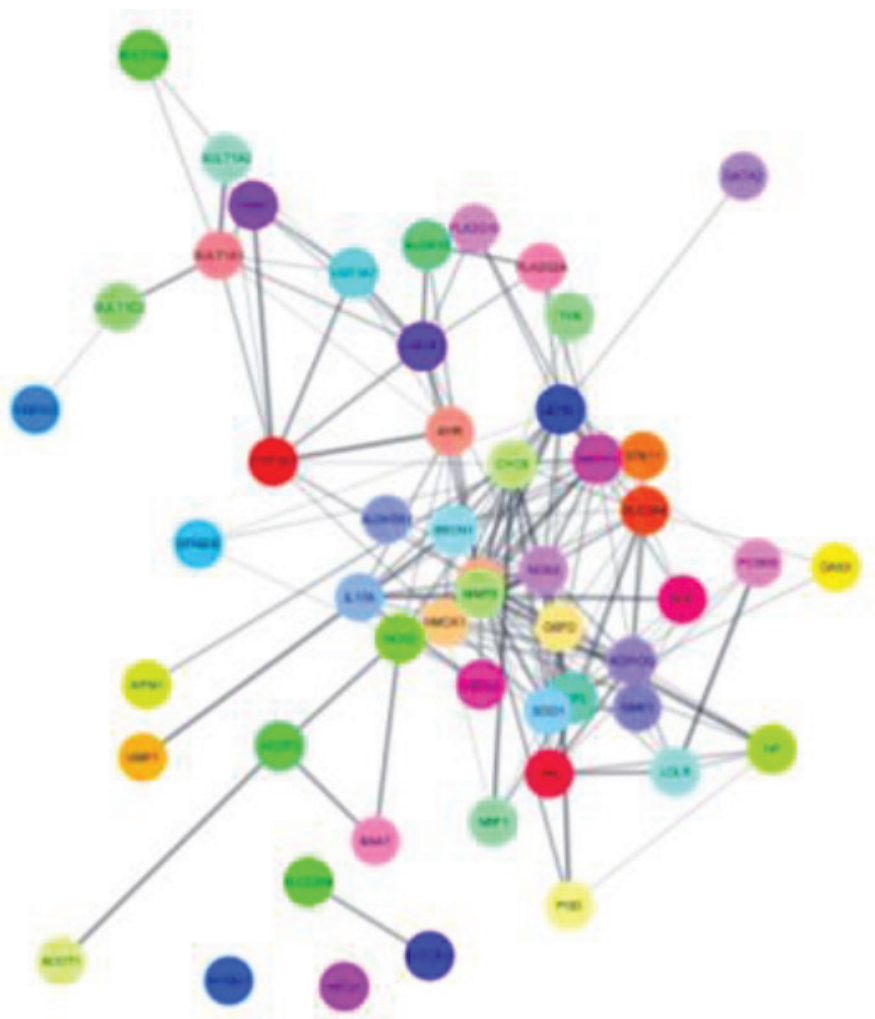

Figure 6: Protein-protein network of selected genes

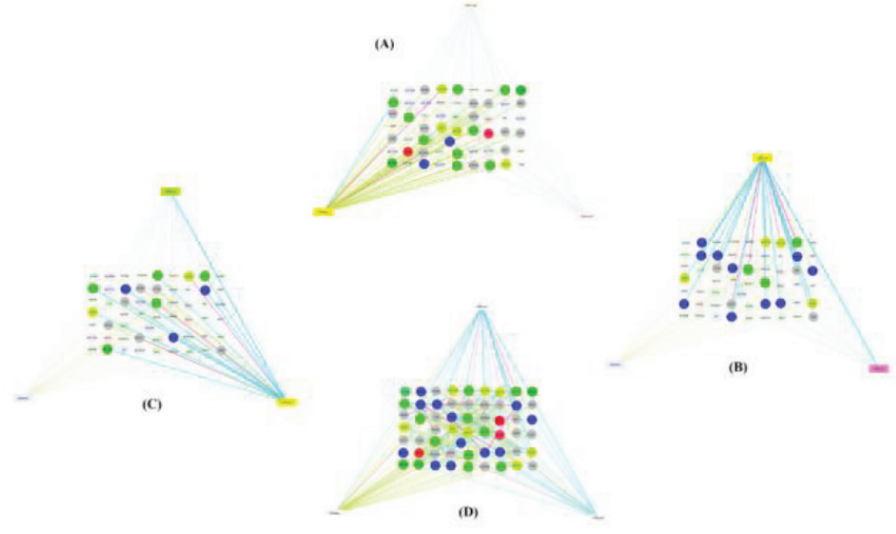

Figure 7: Interaction of active metabolites with selected genes, Figure (A) represents targeted genes of berberine, Figure (B) represents targeted genes of caffeic acid Figure $(C)$ represents targeted genes of ferulic acid where Figure (B) represents the common network of each metabolites and targeted genes.

Computational analyses are the advance tools to explore biological response of drug or plant metabolites based on their gene interaction. Network pharmacology is one of the novel technique to screen hundreds of metabolites based on their biological activity concerning to the targeted sites. ${ }^{[31]}$ The observation of our study revealed the interaction between active metabolites and targeted genes. The analysis showed ferulic acid with significantly interaction with the genes such as MAPK1, MAPK3, UGT1As, G6PD, ACOT2 BAAT etc which regulates inflammation. ${ }^{[32]}$ Glucose-6-Phosphate Dehydrogenase (G6PD) protects these cells from oxidative chemicals while the lack of G6PD causes hemolysis of red blood 

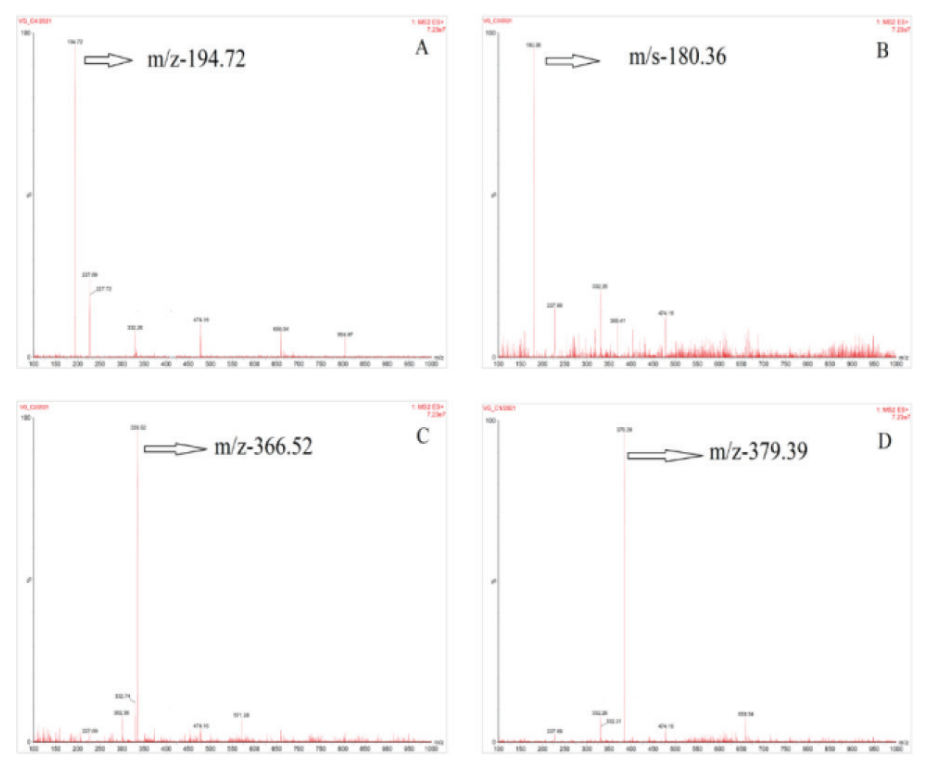

Figure 8: Mass spectra of isolated compounds where (A) showing for compound 1, (B) for compound 2, (C) for compound 3 and (D) for compound 4.
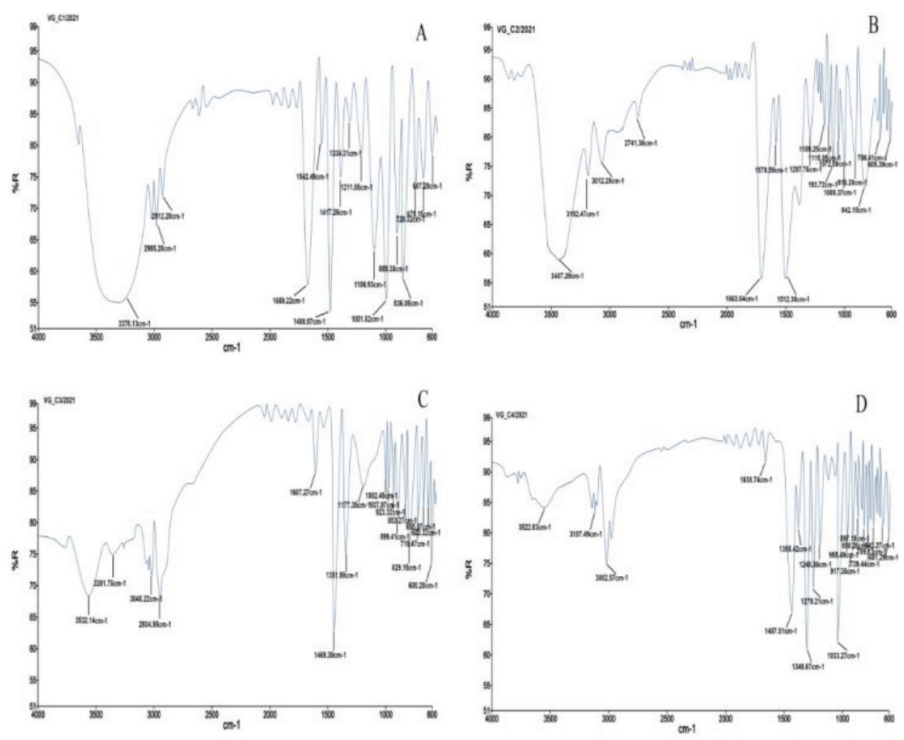

Figure 9: FT-IR spectra of isolated compounds where (A) showing for compound 1, (B) for compound 2, (C) for compound 3 and (D) for compound 4.

cells and represents acute hemolysis. However, the deficiency of G6PD cause Sevier problem of convulsion in the patients chronically associated with hemolysis. ${ }^{[33]}$ The genes of cytosolic sulfotransferases associated with SULTs (SULT1A4, etc) exclusively expressed in neurons with no known function. ${ }^{[34]}$ However SULT4A1 protects against oxidative-stress induced mitochondrial dysfunction in neuronal cells. ${ }^{[34]}$ Ferulic acid, caffeic acid and berberin are the strong candidate which protects the neuronal cells against oxidative and inflammatory stress induced epileptic seizure. In a study cited by revealed that polyphenols such as ferulic acid possess neuroprotective effects against oxidative and inflammatory stress. ${ }^{[35-38]}$ Besides, in the study conducted by Li et al., revealed that berberine strongly attenuates the toxic effects of oxidative and inflammatory stress by amelioration of SOD and reduction of NOS oxidative enzyme, MAPKs and interleukins. ${ }^{[39]}$

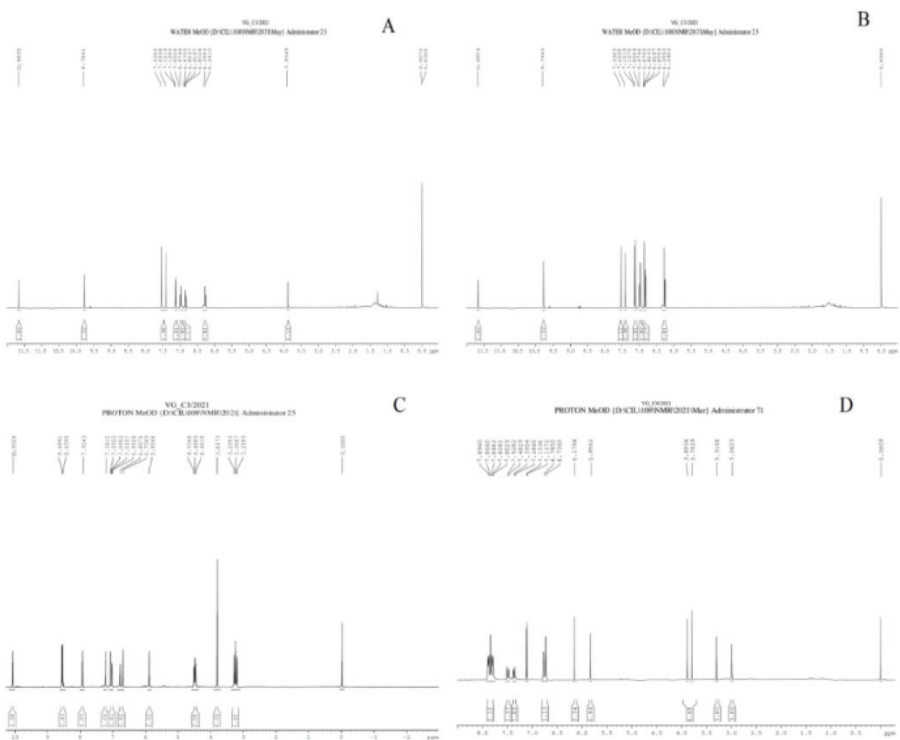

Figure 10: 1HNMR spectra of isolated compounds where (A) showing for compound 1, (B) for compound 2, (C) for compound 3 and (D) for compound

\section{CONCLUSION}

The study concludes that $A$. mexicana is rich in several major and minor metabolites which characterized its chemical complexity. Further, four compounds (ferulic acid, caffeic acid, berberine and angoline) were found as major metabolites and the content of each metabolites found as $3.475 \pm 0.028,1.036 \pm 0.013,0.714 \pm 0.014$ and $0.738 \pm 0.081 \mu \mathrm{g} / \mathrm{mg}$ of the extract, respectively. In computational analysis, it can might be reported that ferulic acid, caffeic acid and berberine are the strong candidate for regulation of epileptic seizure induced by oxidative and inflammatory stress. In view of its study exploration, further experimental analysis are necessary to acknowledge the above biological facts strongly.

\section{ACKNOWLEDGEMENT}

The authors would like to express special thanks to SGT College of Pharmacy, SGT University, Gurugram Haryana, India-122505 for providing assistance and research facilities to complete the study.

\section{CONFLICT OF INTEREST}

The authors declare no conflict of interest.

\section{ABBREVIATIONS}

A. mexicana: Argimone mexicana, HPTLC: High-performance thinlayer chromatography, HPLC: High-performance liquid hromatography, LCMS: Liquid chromatography-mass spectrometry, GCMS: Gas chromatography-mass spectrometry, MS: Mass spectrometric, NMR: Nuclear magnetic resonance, FTIR: Fourier transform infrared spectroscopy, TLC: Thin layer chromatography, CC: Column chromatography, ESI: Electrospray ionization, ADME: Absorption, distribution, metabolism and excretion, GO: Gene Ontology, PPI: Protein-protein interaction

\section{REFERENCES}

1. Sahoo N, Manchikanti P. Herbal drug regulation and commercialization: an Indian industry perspective. J Altern Complement Med. 2013;19(12):957-63. doi: 10.1089/acm.2012.0275, PMID 23829812.

2. Chauhan A, Semwal DK, Mishra SP, Semwal RB. Ayurvedic research and 
methodology: present status and future strategies. Ayu. 2015;36(4):364-9. doi: 10.4103/0974-8520.190699, PMID 27833362.

3. Gaurav, Zahiruddin S, Parveen B, Ibrahim M, Sharma I, Sharma S, Sharma AK, Parveen R, Ahmad S. TLC-MS Bioautography-Based Identification of FreeRadical Scavenging, $\alpha$-amylase, and $\alpha$-glucosidase Inhibitor compounds of Antidiabetic Tablet BGR-34. ACS Omega. 2020;5(46):29688-97. doi: 10.1021/ acsomega.0c02995, PMID 33251404

4. Gad HA, El-Ahmady SH, Abou-Shoer MI, Al-Azizi MM. Application of chemometrics in authentication of herbal medicines: a review. Phytochem Anal. 2013;24(1):1-24. doi: 10.1002/pca.2378, PMID 22678654

5. Lee KM, Jeon JY, Lee BJ, Lee H, Choi HK. Application of metabolomics to quality control of natural product derived medicines. Biomol Ther (Seoul). 2017;25(6):559-68. doi: 10.4062/biomolther.2016.249, PMID 28605829.

6. Tistaert C, Dejaegher B, Vander Heyden Y. Chromatographic separation techniques and data handling methods for herbal fingerprints: a review. Anal Chim Acta. 2011;690(2):148-61. doi: 10.1016/i.aca.2011.02.023, PMID 21435470.

7. Sharma S, Baboota S, Amin S, Mir SR. Ameliorative effect of a standardized polyherbal combination in methotrexate-induced nephrotoxicity in the rat. Pharm Biol. 2020:58(1):184-99. doi: 10.1080/13880209.2020.1717549, PMID 32083987

8. Arunadevi R, Murugammal S, Kumar D, Tandan SK. Evaluation of Caesalpinia bonducella flower extract for anti-inflammatory action in rats and its high performance thin layer chromatography chemical fingerprinting. Indian J Pharmacol. 2015;47(6):638-43. doi: 10.4103/0253-7613.169582, PMID 26729956.

9. Dar AA, Sangwan PL, Khan I, Gupta N, Qaudri A, Tasduq SA, Kitchlu S, Kumar A, Koul S. Simultaneous quantification of eight bioactive secondary metabolites from Codonopsis ovata by validated high performance thin layer chromatography and their antioxidant profile. J Pharm Biomed Anal. 2014;100:300-8. doi: 10.1016/j.jpba.2014.07.034, PMID 25194343

10. Shanaida M, Jasicka-Misiak I, Makowicz E, Stanek N, Shanaida V, Wieczorek PP. Development of high-performance thin layer chromatography method for identification of phenolic compounds and quantification of rosmarinic acid content in some species of the Lamiaceae family. J Pharm Bioallied Sci. 2020;12(2):139-45. doi: 10.4103/jpbs.JPBS_322_19, PMID 32742112.

11. Brahmachari G, Gorai D, Roy R. Argemone mexicana: chemical and pharmacological aspects. Revista Brasileira de Farmacognosia. 2013:23(3):559-75. doi: 10.1590/S0102-695X2013005000021.

12. Asuntha G, Raju YP, Sundaresan CR, Rasheed A, Chowdary VH, Vandana KR, Babu KS, Prasad KV. Effect of Argemone mexicana (L.) against lithium-pilocarpine induced status epilepticus and oxidative stress in Wistar rats. Indian J Exp Biol. 2015;53(1):31-5. PMID 25675709.

13. More NV, Kharat AS. Antifungal and anticancer potential of Argemone mexicana L. Medicines (Basel). 2016;3(4). doi: 10.3390/medicines3040028, PMID 28930138

14. Upasani SV, Beldar VG, Tatiya AU, Upasani MS, Surana SJ, Patil DS. Ethnomedicinal plants used for snakebite in India: a brief overview. Integr Med Res. 2017;6(2):114-30. doi: 10.1016/j.imr.2017.03.001, PMID 28664135

15. Elizondo-Luevano JH, Verde-Star J, González-Horta A, Castro-Ríos R, HernándezGarcía ME, Chávez-Montes A. In vitro Effect of Methanolic Extract of Argemone mexicana against Trichomonas vaginalis. Korean J Parasitol. 2020;58(2):135-45. doi: 10.3347/kjp.2020.58.2.135, PMID 32418382

16. Farahmandfar R, Esmaeilzadeh Kenari R, Asnaashari M, Shahrampour $D$, Bakhshandeh T. Bioactive compounds, antioxidant and antimicrobial activities of Arum maculatum leaves extracts as affected by various solvents and extraction methods. Food Sci Nutr. 2019;7(2):465-75. doi: 10.1002/fsn3.815, PMID 30847124

17. Mukherjee PK, Rai S, Bhattacharya S, Wahile A, Saha BP. Marker analysis of polyherbal formulation, Triphala - A well known Indian traditional medicine. Indian J Tradit Knowl. 2008.

18. Prasad D, Sati SP. A new 2,8-dihydroxy-1,6-dimethoxy xenthones from cythula tomesntosa. Orient J Chem. 2011.

19. Asthana RK, Sharma NK, Kulshreshtha DK, Chatterjee SK. A xanthone from Swertia chirayita. Phytochemistry. 1991;30(3):1037-9. doi: 10.1016/00319422(91)85308-M

20. Hosseini SM, Abbasalipourkabir R, Jalilian FA, AsI SS, Farmany A, Roshanaei G, Arabestani MR. Doxycycline-encapsulated solid lipid nanoparticles as promising tool against Brucella melitensis enclosed in macrophage: A pharmacodynamics study on J774A.1 cell line. Antimicrob Resist Infect Control. 2019;8:62. doi: 10.1186/s13756-019-0504-8, PMID 30988946.

21. Mallavadhani UV, Aparna Y, Mohapatra S, Mane DV. Quantitative evaluation of Boerhavia diffusa and its commercial formulations with respect to its major bioactive marker, eupalitin galactoside, using high-performance thinlayer chromatography. JPC - Journal of Planar Chromatography - Modern TLC 2017;30(6):521-6. doi: 10.1556/1006.2017.30.6.10.

22. Sajjadi SE, Shokoohinia Y, Moayedi NS. Isolation and identification of ferulic acid from aerial parts of Kelussia odoratissima Mozaff. Jundishapur J Nat Pharm Prod. 2012;7(4):159-62. doi: 10.17795/jnpp-4861, PMID 24624175.

23. Swisłocka R. Spectroscopic (FT-IR, FT-Raman, UV absorption, $1 \mathrm{H}$ and 13C NMR and theoretical (in B3LYP/6-311 $++G^{* *}$ level) studies on alkali metal salts of caffeic acid. Spectrochim Acta A Mol Biomol Spectrosc. 2013;100:21-30. doi: 10.1016/i.saa.2012.01.048, PMID 22369898.

24. Battu SK, Repka MA, Maddineni S, Chittiboyina AG, Avery MA, Majumdar S Physicochemical characterization of berberine chloride: A perspective in the development of a solution dosage form for oral delivery. AAPS PharmSciTech. 2010;11(3):1466-75. doi: 10.1208/s12249-010-9520-y, PMID 20842541.

25. Lee SK, Qing WG, Mar W, Luyengi L, Mehta RG, Kawanishi K, Fong HHS, Beecher CWW, Kinghorn AD, Pezzuto JM. Angoline and chelerythrine, benzophenanthridine alkaloids that do not inhibit protein kinase C. J Biol Chem 1998;273(31):19829-33. doi: 10.1074/jbc.273.31.19829.

26. Fernandes CC, Vieira PC, Silva VCd, Dall'Oglio EL, Silva LEd, Sousa PTd. 6-acetonyl-N-methyl-dihydrodecarine, a new alkaloid from Zanthoxylum riedelianum. $J$ Braz Chem Soc. 2009;20(2):379-82. doi: 10.1590/S0103-50532009000200025.

27. Daina A, Michielin O, Zoete V. SwissADME: A free web tool to evaluate pharmacokinetics, drug-likeness and medicinal chemistry friendliness of small molecules [sci rep]. Sci Rep. 2017;7:42717. doi: 10.1038/srep42717, PMID 28256516.

28. LiY, Wang L, Xu B, Zhao L, Li L, Xu K, Tang A, Zhou S, Song L, Zhang X, Zhan H. Based on network pharmacology tools to investigate the molecular mechanism of Cordyceps sinensis on the treatment of diabetic nephropathy. J Diabetes Res. 2021;2021:8891093. doi: 10.1155/2021/8891093, PMID 33628839.

29. Heinrich M. Quality and safety of herbal medical products: regulation and the need for quality assurance along the value chains. $\mathrm{Br} J$ Clin Pharmacol. 2015;80(1):62-6. doi: 10.1111/bcp.12586, PMID 25581270.

30. LiY, Hu Z, He L. An approach to develop binary chromatographic fingerprints of the total alkaloids from Caulophyllum robustum by high performance liquid chromatography/diode array detector and gas chromatography/mass spectrometry. J Pharm Biomed Anal. 2007;43(5):1667-72. doi: 10.1016/j.jpba.2006.12.028, PMID 17291705.

31. Yi F, Li L, jia $X L$, Meng H. Dong Y mao, Liu $\mathrm{H}$ bo, et al. In silico approach in reveal traditional medicine plants pharmacological material basis. Chin Med (United Kingdom). 2018

32. Zhang J, Zheng C, Yuan S, Dong X, Wang L, Wang Y, Wang W, Gao K, Liu J. Uncovering the pharmacological mechanism of Chaibei Zhixian decoction on epilepsy by network pharmacology analysis. Evid Based Complement Alternat Med. 2019;2019:3104741. doi: 10.1155/2019/3104741, PMID 31214268

33. Merdin A, Avci F, Guzelay N. Glucose-6-phosphate dehydrogenase deficiency presented with convulsion: A rare case. Hematol Rep. 2014:6(1):5266. doi: 10.4081/hr.2014.5266, PMID 24711919.

34. Hossain MI, Marcus JM, Lee JH, Garcia PL, Gagné JP, Poirier GG, Falany CN, Andrabi SA. SULT4A1 protects against oxidative-stress induced mitochondrial dysfunction in neuronal cells. Drug Metab Dispos. 2019;47(9):949-53. doi 10.1124/dmd.119.088047, PMID 31266751

35. Szwajgier D, Borowiec K, Pustelniak K. The neuroprotective effects of phenolic acids: molecular mechanism of action. Nutrients. 2017;9(5). doi: 10.3390/ nu9050477, PMID 28489058.

36. Singh T, Kaur T, Goel RK. Ferulic acid supplementation for management of depression in epilepsy. Neurochem Res. 2017:42(10):2940-8. doi: 10.1007/ s11064-017-2325-6, PMID 28608235.

37. Coelho VR, Vieira CG, de Souza LP, da Silva LL, Pflüger P, Regner GG, Papke DK, Picada JN. Pereira P. Behavioral and genotoxic evaluation of rosmarinic and caffeic acid in acute seizure models induced by pentylenetetrazole and pilocarpine in mice. Naunyn Schmiedebergs Arch Pharmacol. 2016;389(11):1195-203. doi: 10.1007/s00210-016-1281-z, PMID 27476160

38. Sadeghnia HR, Taji AR, Forouzanfar $F$, Hosseinzadeh $H$. Berberine attenuates convulsing behavior and extracellular glutamate and aspartate changes in 4-aminopyridine treated rats. Iran J Basic Med Sci. 2017:20(5):588-93. doi: 10.22038/IJBMS.2017.8756, PMID 28656093.

39. Li Z, Geng YN, Jiang JD, Kong WJ. Antioxidant and anti-inflammatory activities of berberine in the treatment of diabetes mellitus. Evid Based Complement Alternat Med. 2014;2014:289264. doi: 10.1155/2014/289264, PMID 24669227. 
GRAPHICAL ABSTRACT

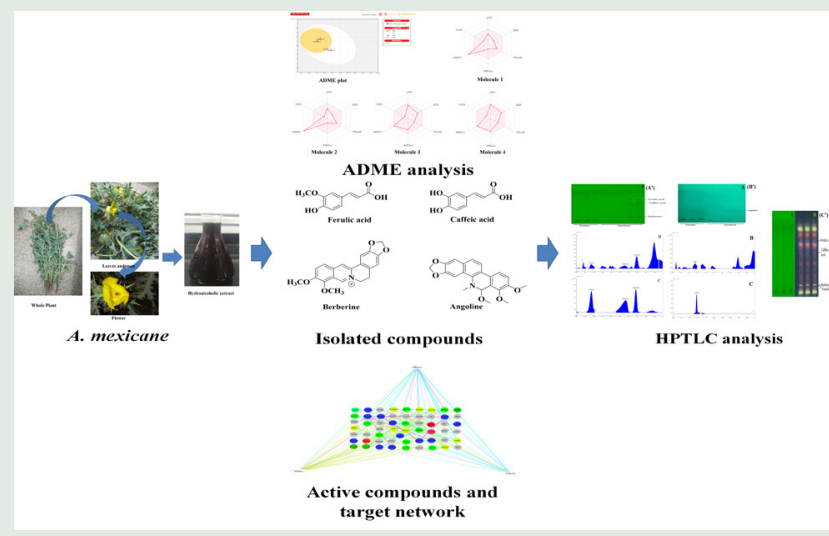

\section{SUMMARY}

Traditional Indian medicines play an important role against several ailments. A. mexicana is an Indian medicinal plants used for the treatment of asthma, ulcers, dysentery etc. Due to lack of phytopharmacological evidences and molecular mechanistic evaluation, the study is associated to evaluate the phytochemicals and antiepileptic potential of A. mexicana using analytical and computational tools. The study revealed ferulic acid, caffeic acid, berberine and angoline as the major constituents of this plant. These phytochemicals are potentially exhibited to mitigate the oxidative and inflammatory stress induced epileptic seizure. In active compound network analysis it can be clearly define that the identified constituents having significant interaction with the selected targets. In GO analysis, the selected targets are potentially associated with brain disorder, oxidative and inflammatory stress etc. Hence, it can prove that $A$. mexicana possess several metabolites which play a protective role in against oxidative and inflammatory stress induced epileptic seizure.

\section{ABOUT AUTHORS}

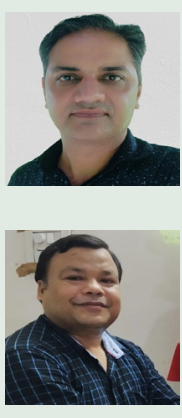

Mr. Vinod Gahlot is currently working as Associate Professor at Department of of Pharmacology, Gurugram Global College of Pharmacy, Affiliated to Pt. B. D. Sharma University of Health Sciences, Rohtak. His main areas of research include diabetic nephropathy, anti-hypertensives and brain disorders incuding epilepsy and stereotypy.

Dinesh Kumar Yadav, M.Pharm. PhD, is currently Associate Professor in the Department of Pharmacognosy at SGT, University Gurugram, Haryana. His main areas of research Isolation of phytoconstituents, Analysis of crude drugs, Pharmacognostical, Physicochemical, Pharmacological screening of medicinal plants and also development of herbal formulation.

Cite this article: Gahlot V, Yadav DK. Phytochemical and Network Pharmacology based Evaluation of Oxidative and Inflammatory Stress Induced Antiepileptic Potential of Identified Metabolites of Argemone mexicana L. Pharmacog Res. 2021;13(4):208-17. 